\title{
Autoconhecimento por meio do corpo do outro: quando um curso de idiomas se abre ao teatro da vida
}

\section{La reconnaissance de soi à travers le corps de l'autre: quand un cours de langue orale ouvre sur le théâtre de la vie}

Graça dos Santos ${ }^{1}$

Tradução: Tiago Cruvinel ${ }^{2}$

Original: In: Gilles Louÿs et Emmanuelle Sauvage (Sous la direction de) De la singularité dans la communication interculturelle: approches transdisciplinaires, Paris, L'Harmattan, 2014, p. 175-182 


\section{Resumo}

Este artigo tem com objetivo analisar as relações entre as pedagogias do ensino de linguagem e o teatro, principalmente, no que diz respeito às propostas do artista como pedagogo a partir da visão teórica e prática de Antoine Vitez e dos estudos da Sociologia do corpo.

Palavras-chave: Pedagogia do Ensino. Teatro. Gesto Aumentado. Corpo.

\section{Abstract}

Cet article a pour objectif d'analyser les relations entre les pédagogies de l'enseignement de la langue et du théâtre, en particulier en ce qui concerne les propositions de l'artiste en tant que pédagogue à partir du point de vue théorique et pratique d'Antoine Vitez et sur les études de la sociologie du corps.

Keywords: Pédagogie de l'enseignement. Théâtre. Le geste augmenté. Corps.

\footnotetext{
1 Professora doutora de universidades portuguesas e da Universidade Paris Ouest Nanterre La Défense onde dirige o CRILUS (EA369 Etudes Romance). Diretora, atriz e professora de teatro, escreve sobre as noções do corpo físico/corpo social, as representações cênicas do corpo do povo, a ditadura salazarista e a censura. Publicou numerosos artigos sobre a história do espetáculo europeu e do teatro português. Idealizadora e coordenadora do Parfums du Lisbonne, festival de teatro que mobiliza o teatro universitário de Paris.

2 Professor doutor, do Instituto Federal de Minas Gerais (IFMG). tiago.brito.cruvinel@gmail.com
} 
O teatro é o lugar por excelência do desvelamento. [...]. Pois a cena é o lugar onde a profundidade se torna aparente. (Glissant, 2010, p. 67)

\title{
1 - O desejo pelo gesto aumentado 3 / descobrir o inesperado
}

\begin{abstract}
Eu me posiciono entre os alunos e de repente vejo, na relação arriscada dos corpos entre eles, no palco, um sentido/significado que não tinha imaginado, que eles não tinham imaginado por eles mesmos e eu os mostro neste sentido, [...] eu refaço para eles o que eles não tinham percebido [...] E eu não imponho nada vindo de mim, mas capto a vontade que pensei adivinhar de um gesto e de um prolongamento desta vontade pelo gesto aumentado [...]. (Vitez, 2006, p. 6)
\end{abstract}

Nós partiremos dessa citação de Antoine Vitez (1930-1990) para expor os processos desencadeados em uma oficina bilíngue que combina as pedagogias do ensino de linguagem e do teatro. Veremos como os paralelos com "o teatro da vida" fazem sentido quando o curso permite a todos passar da representação inconsciente para a consciente: as evidências invisíveis são fundidas em "gesto aumentado" que permitem desvendar o corpo hexis (Bourdieu, 1980) em que a interculturalidade toca o indivíduo, a sua cultura e o seu grupo social.

As propostas citadas são, antes de tudo, uma referência ao artista como pedagogo que fala dos seus estudantes, que evoca, enlaçando o seu corpo entre os corpos de seus estudantes. Essa intensa presença física é contrabalançada pela consciência súbita do significado, não definitivo, dessa relação e do olhar sobre ela. O que é definido aqui como "arriscado" diz respeito à irrupção descontrolada de significados possíveis cuja interpretação é aberta. A repetição recíproca do potencial imaginário (o de Antoine Vitez e o dos atores aprendizes que ele formou) enfatiza o caráter aberto da relação e de sua leitura, fazendo, assim, com que todos os corpos vivos se tornem linguagem. O diretor não é apresentado em função do espetáculo que criaria, mas como um transeunte, um tradutor de sinais descontrolados emitidos pelos estudantes/atores; ele é quase um adivinho que antecipa o gesto antes dele aparecer; uma lupa, um vidro grosso, que permite ao emissor do gesto ir ao seu encontro, mesmo que ele possa não ter nascido ainda. Não é uma questão para o artista formador se impor, mas de adivinhar, de preceder à vontade, ou seja, o desejo do movimento na sua fonte e, em seguida, ampliá-lo.

É uma forma de busca pelo inesperado que revela um desapego, a ausência de autocontrole furtivo que só é possível por um trabalho anterior, com o grupo constituído, que implica em uma grande confiança mútua. As propostas do artista como pedagogo transparecem uma extrema precaução na vontade de estar atento e restaurar o que foi sentido sem impor nada, destacando a fragilidade da situação feita pelo acaso observado e seguido de uma reflexão. $O$ assunto aqui centra-se na relação obtida deste corpo dentre os outros corpos e centra-se na atenção e na precisão da observação do outro em movimento; além do sentido potencial das ações

\footnotetext{
3 De acordo com Antoine Vitez (In: A.Vitez, « Réflexions sur l'école », L'art du théâtre, n 8, Arles, Actes Sud, 1988, p. 32.) , ele gosta de utilizar os verbos que veem da música, como "aumentar" e "diminuir", a invés de usar as que fazem referência apenas ao espaço, como "ampliar" ou "encolher". Para o leitor de língua portuguesa, a expressão gesto ampliado faria mais sentido. No entanto, decidimos manter a expressão "gesto aumentado" (le geste augmenté) entendo que ele dialoga mais com o sentido atribuído pelo autor e citado por Graças do Santos [Nota do tradutor].
} 
realizadas e que se tornaram "gesto aumentado". O que Antoine Vitez evoca é, finalmente, o instante frágil e tênue que se atinge, esse ínfimo momento em que se decifra a invisibilidade das evidências da corporeidade, da qual se capta um significado inesperado além do óbvio. As propostas deste homem de teatro - renomado e considerado um mestre pelos atores que trabalharam com ele - revelam processos para uma pedagogia sustentada pela escuta e pelo respeito aos outros, uma atenção extrema e sensível. Nós estamos na intersecção entre a cena teatral e o teatro da vida, um espaço onde a arte dramática está na própria origem da existência humana e que permite a humanidade se sentir melhor e compreender os seus caminhos da vida.

\section{2 - O teatro da vida e suas traduções}

Existir, significa, em princípio, mover-se em um espaço e no tempo, transformar o seu ambiente graças a soma de gestos eficientes, classificar e atribuir um significado e um valor a inumeráveis estímulos do ambiente por meio de atividades perceptivas, para entregar um repertório de gestos e de mímicas, um conjunto de rituais corporais com o apoio de outros (Le Breton, 2010, p. 4).

A mudança da linguagem teatral para a sociologia do corpo é pouco perceptível, pois os campos parecem se sobrepor. O que está sendo colocado aqui são os jogos físicos de cada ser humano, que estão sob sistemas simbólicos, e que são constituídos por referências culturais e que se abrem mais amplamente ao teatro da vida e suas realizações. A existência é, a princípio, corporal e o contexto social molda o corpo que se torna um "vetor semântico", destacando sua relação com o mundo, com elementos que vão desde a expressão de sentimentos; das etiquetas dos rituais de interação às encenações para a aparência. Seja ele emissor ou receptor, o corpo produz perpetuamente um sentido/significado e acrescenta a humanidade um espaço social e cultural que lhes é dado.

Os sociólogos e os antropólogos analisaram bem essa construção social e as pesquisas sobre essas questões estão longe do fim. Marcel Mauss, em especial, quando define "as técnicas do corpo" por "as maneiras pelas quais a humanidade, sociedade em sociedade [geração em geração], de uma maneira tradicional, sabem usar seus corpos" (Mauss, 1950, p. 365); o que interessa ao pesquisador é ver como a educação e a tradição imprimem as marcas culturais indeléveis nos corpos (Jacquet, 2001, p. 12). Outras correntes sociológicas estão mais interessadas pelas diferenças sociais e sexuais que moldam os padrões corporais. Assim, Pierre Bourdieu, que percebe o corpo como um produto sociocultural e "a relação com o corpo não se prende diretamente à imagem a que nos referimos aos outros, mas a certos modelos do corpo" legítimo "que regulam a avaliação a esta imagem em função da posição dos sujeitos na estrutura social" (Maisonneuve, Bruchon-Schweitzer, 1981, p. 84). Por sua parte, Merleau-Ponty enfatiza que "a organização anatômica do corpo deixa em aberto uma série de possibilidades para que suas instruções não sejam entregues de uma vez por todas, as chaves nas mãos, mas que seja inventada; a exemplo da linguagem, ela deve, portanto, ser decifrada como tal" (Jacquet, 2001, p. 188). Noam Chomsky e Michel Foucault evocam o desenvolvimento da "natureza humana" como um concei- 
to biológico e as pesquisas sobre a linguagem assumem uma grande importância que podemos perceber, com Claude Hagège, que conceitua o homem como "énonceur psychosocial" (enunciador psicossocial). Essa reflexão sobre o comportamento humano e sobre o lugar do corpo na sociedade também é enriquecida pelo desenvolvimento das ciências cognitivas e, em particular, pelas neurociências.

\title{
3 - Palavras e corpos para dizer
}

Enquanto evocamos uma "filosofia" do corpo, as diferentes maneiras de fazer do corpo, consigo mesmo e com os outros, as práticas e as análises sobre esses temas não deixam de proliferar. Parece que o teatro e seu campo de reflexão (e as propostas de Antoine Vitez são emblemáticas a este respeito) permitem abordar o assunto de uma maneira concreta, eu diria, e é quase um pleonasmo, tornar-se pesquisa a partir desse assunto, isto é, de entrar no assunto de maneira concreta e tangível.

\begin{abstract}
O teatro serve para domesticar o tempo e o espaço-tempo de um encontro de seres humanos que vêm ver outros seres humanos emprestar seus corpos e suas vozes a seres humanos fictícios. Histórias de seres humanos fictícios serve para representar o mundo que nos contém e para mantê-lo ao nosso redor, dentro de uma jaula de espetáculo. Representar o mundo serve para examiná-lo. Examinar o mundo serve para conhecê-lo. (Cormann, 2003, p.73)
\end{abstract}

Essa definição do dramaturgo Enzo Cormann ecoa a do sociólogo David Le Breton já citado acima: "Existir significa primeiro mover-se em um espaço e no tempo...". Novamente vê-se a linguagem da sociologia e a do teatro em um espelho quase idêntico. A primeira diferença desses dois espaços diz respeito à realidade do que é representado: a vida real de um lado, a sua representação imaginária do outro. Mas se o ator/a atriz toma a existência de um outro, escrito, e ele/ela o interpreta física e vocalmente para ser visto por outros reunidos para esse propósito, o que é interpretado é inspirado na vida real e concreta.

A representação teatral do mundo oferece um olhar singular sobre ele, mundo este caracterizado pelas políticas opressivas das mídias de massa e pelas políticas consensuais infantilizantes. Sua crítica das representações dominantes não tem nada de teórica. Seu olhar não é um olhar metafórico, uma "visão da mente", mas um olhar concreto sobre pessoas, palavras e coisas. (Cormann, 2003, p. 77)

É esse "olhar concreto" que nos interessa e que nos leva ao "exame do mundo" e ao "conhecimento". Não é este o propósito do professor/a, que tem a missão de levar seus estudantes para além de si mesmos?

\section{4 - Iniciação à viagem ou a eclosão da palavra e do corpo}

É evidente que a prática do teatro leva a uma consciência do corpo portador de uma articulação, uma voz, ferramentas estas essenciais para o bom domínio de um idioma, para descobrir todas as potencialidades. Aproveitando nossa prática com as Artes Cênicas e nossas atividades ligadas às artes do espetáculo, oferecemos nossas aulas 
de idioma como um workshop bilíngue. A partir de uma língua matriz (na maioria das vezes, em francês), propomos um caminho para pelo menos um outro idioma. Essa é uma maneira de sugerir uma outra abordagem/experiência da noção de linguagem tanto na linguística quanto no teatro. Sem querer instrumentalizar o teatro, é evidente que a prática desta arte leva a uma consciência do corpo portador de uma articulação, uma voz e ferramentas essenciais para o bom domínio de uma língua cujas as potencialidades dos sujeitos serão descobertas por nós. As oficinas são, assim, o local de eclosão das capacidades, muitas vezes desconhecidas, que todos são portadores; essa descoberta individual é acompanhada por uma jornada em comum dentro do grupo constituído.

Como atriz bilíngue francês/português sem sotaque, a prática cênica das línguas de Molière e Gil Vicente me permite pesquisar os dois idiomas, de buscar suas comunicações, seus interstícios (Dos Santos, 2012). O bilinguismo e o que isso implica por seus contrastes fonéticos e linguísticos e suas consequências no trabalho do ator/atriz é aqui um elemento/ferramenta fundamental. Os participantes podem atuar consecutivamente em francês e depois em português ou outro idioma de sua escolha. Eles também podem igualmente misturar as línguas: dando corpo às diferenças em sua articulação, eles tornarão imediatamente visíveis as mutações e as variações operadas no momento de carregar uma outra língua, de colocá-la em movimento no sentido apropriado. Assim, chegamos perto das ciências da linguagem enquanto nos envolvemos no campo da interculturalidade. A partir de uma língua matriz, comum a todos, abrimos o campo das comparações. Na realidade, percebe-se que o idioma usado como base de comunicação durante as oficinas não é o mesmo de acordo com os sujeitos falantes, difere segundo as suas percepções e as peculiaridades de cada um; imediatamente deve-se aguçar esse sentido: todo mundo tem uma voz diferente, uma articulação, uma prosódia pessoal... É uma forma de apropriação da linguagem, muitas vezes inconsciente, que reflete a experiência afetiva e psíquica de cada um, a maneira como se adquire e se domina a linguagem.

Trata-se, portanto, em um primeiro momento, de ter a consciência da sua própria maneira de falar a sua língua. Isto é tanto uma forma de introspecção do indivíduo analisando seu corpo, portador de sua voz e de seu discurso - um trabalho de precisão - quanto da observação da sua capacidade de formular os elementos a partir dos lugares mais recônditos de si mesmo. A oficina cumpre plenamente o seu papel a partir dos seguintes pontos: antes de discutir a palavra articulada, devemos compreender a respiração, a voz e, mais amplamente, o corpo e as premissas fundamentais que impulsionam o ar para as cordas vocais. $O$ ator/a atriz, em seguida, entende que todo o seu corpo abraça e impulsiona sua voz, suas palavras e a sua língua... O papel do grupo constituído no workshop é fundamental: o indivíduo que nos une percebe as características do nosso ser exterior, de maneira mais imediata e aguda; ele nos devolve, ele formula esse outro eu oculto presentes em nós. Às vezes, essa observação dos outros se torna propícia ao espelho. Ao sair em busca do outro latente em si, encontramos e observamos que o outro está ao nosso redor e assim aprendemos a nos observar e a nos ouvir melhor. 


\section{5 - As evidências invisíveis são fundidas em "gesto aumentado"}

A observação e a transição para outras línguas são assim possíveis e facilitadas. É uma abordagem quase lúdica, que primeiro separa o significado do som. A partir de uma observação quase clínica do aparelho fonatório que se adapta a um outro idioma, nos redescobrimos apropriando-nos da segunda língua. $O$ ator/a atriz aprende aqui, observando a si mesmo, a se disponibilizar para receber uma linguagem, uma palavra, um texto, um papel. Extrapolando a estrita noção linguística do conceito de "bilinguismo", conseguimos explorar o trabalho dos atores de maneira inesperada. É preciso fazer respirar duas línguas no corpo do ator/da atriz; é a circulação que se opera no corpo em direção à voz, ressoando o significado, o contexto. Essa deambulação virá para favorecer a duplicação necessária ao ator/a atriz para se transfigurar ao descobrir e dar lugar aos personagens escondidos nele. $O$ ator/a atriz passa a revelar forças e vozes até então ocultas; em busca do outro em si mesmo, ele revela a alteridade humana de uma maneira quase mágica. Já o teatro, o espetáculo: dá, para aqueles que assistem, a visão cênica dos outros "eles mesmos" em uma representação da vida. Isto porque é uma questão de abertura à imaginação, ao que Edouard Glissant (2010, p. 53) chama de "o imaginário das linguagens", para abordar a língua "aberta ou fechada", ele chama de "o imaginário das humanidades. Não se trata mais de ser bilíngue, mas multilíngue: A palavra está ligada a uma paisagem, a uma época, mas ela tenta encontrar todas as paisagens e todos os tempos do mundo" (Glissant, 2010, p. 63).

Quando apresenta o seu trabalho sobre a sociologia do corpo, David Le Breton nomeia de "ator" o sujeito em ação; pouco a pouco, nós mesmos passamos a usar o termo depois de falar de "alunos", "estudantes" ou "participantes", e queremos repetir a frase "ser ator da sua vida" - ou seja, ter a capacidade de se ver, agir e de compreender para além das evidências automáticas. "A desenvoltura está ligada à adequação do papel à crença de que se está no lugar certo, que o papel, para usar terminologias interacionistas, é validado pelas normas vigentes" (Goffman, 1973, p. 56), diz o sociólogo e linguista Erving Goffman. Mas essa desenvoltura implica uma reflexão, um retorno sobre si mesmo de que o trabalho em oficina possibilitará se lançar em favor de um comportamento autônomo e consciente; como tal, a abordagem de Vitez aponta para o caminho duplo da busca, um caminho a percorrer: o do estudante e o do professor/da professora. Vimos o quanto os paralelos com "o teatro da vida" fazem sentido no momento em que o curso permite que todos passem da representação inconsciente para a consciente: as evidências invisíveis são fundidas em "gesto aumentado", o que permite desvendar o corpo hexis onde o intercultural toca o indivíduo, sua cultura e seu grupo social. "O professor não pode deixar seu etnocentrismo linguístico e cultural para descobrir que a linguagem, que ele usa espontaneamente em seu ensino, é a de uma classe social, sem perceber, ao mesmo tempo, que a língua falada espontaneamente pelos estudantes deve essencialmente suas características, aprovadas ou culpadas, à sua origem social" (Bourdieu; Passeron, 1965, p. 463). O objetivo é tornar explícitas todas essas pressuposições e levar a uma transmissão explícita que revela as opacidades admitidas (as evidências invisíveis). 
"A formação do ator é, portanto, feita pela inteligência de si mesmo" (Vitez, 2006, p. 119) nos diz novamente Antoine Vitez, como para confirmar que o teatro em língua estrangeira é um caminho que se abre aos estudantes para a sua afirmação como membros de uma comunidade, ultrapassando as fileiras, as barreiras psicológicas e sociais, bem como o anonimato em que o sistema universitário muitas vezes nos mergulha. Da mesma forma, a ligação com o mundo da criação artística, bem como a dimensão mais antropológica da cultura (especialmente a interculturalidade mobilizada através de práticas expressivas) aparecem como pontos chaves para os estudantes/atores sendo, acima de tudo, sujeitos de si mesmos conscientes autores/atores de suas próprias vidas.

\section{Referências}

ANDRIEU, Bernard, La nouvelle philosophie du corps, Ramonville Saint-Agne, Editions Erès, 2002.

BOURDIEU, Pierre et PASSERON, Jean-Claude, « Langage et rapport au langage dans la situation pédagogique », Les temps modernes, $n^{\circ} 232$, septembre 1965, p. 435-466.

BRAUNSTEIN, Florence et PÉPIN Jean-François, La place du corps dans la culture occidentale, Paris, Presses Universitaires de France, 1999.

CORMANN, Enzo, A quoi sert le théâtre?, Besançon, Les Solitaires Intempestifs, 2003.

DETREZ, Christine, La construction sociale du corps, Paris, Editions du Seuil, 2002.

DOS SANTOS, Graça, " Passages du corps à la voix ; à la recherche de l'autre : vers l'acteur bilingue », Voix : imaginaires et cultures de langue portugaise, revue Plural/ Pluriel, $n^{\circ} 10,2012$. Revue en ligne: http://www.pluralpluriel.org/.

GLISSANT, Édouard, L'imaginaire des langues, entretiens avec Lise Gauvin (19912009), Paris, Gallimard, 2010.

GOFFMAN, Erving, La mise en scène de la vie quotidienne, Paris, Éditions de Minuit, 1973.

GUÉNOUN, Denis, L'Exhibition des mots et autres idées du théâtre et de la philosophie, Belfort, 1998, Editions Circé.

JACQUET, Chantal, Le corps, Paris, 2001, Presses Universitaires de France.

LE BRETON, David, La sociologie du corps, Paris, 7e édition mise à jour, « Que sais-je », Presses Universitaires de France, 2010.

MAISONNEUVE, Jean et BRUCHON -SCHWEITZER, Marilou, Modèles du corps et psychologie esthétique, Paris, Presses Universitaires de France, 1981. 
MARZANO PARISOLI, Maria Michela, Penser le corps, Paris, Presses Universitaires de France, 2002.

MAUSS, Marcel, « Les techniques du corps », Sociologie et anthropologie, Paris, Presses Universitaires de France, 1950.

VITEZ, Antoine, Antoine Vitez, Arles, Actes Sud, 2006.

Recebido em: 10/02/2019 Aprovado em: 10/02/2019 